\title{
Optimal Protection Coordination for Microgrid under Different Operating Modes
}

\author{
Ming-Ta Yang and Li-Feng Chang \\ Department of Electrical Engineering, St. John's University, Section 4, 499 Tam King Road, Tamsui District, \\ New Taipei City 25135, Taiwan
}

Correspondence should be addressed to Ming-Ta Yang; mtyang@mail.sju.edu.tw

Received 11 July 2013; Accepted 12 November 2013

Academic Editor: Jonathan N. Blakely

Copyright (C) 2013 M.-T. Yang and L.-F. Chang. This is an open access article distributed under the Creative Commons Attribution License, which permits unrestricted use, distribution, and reproduction in any medium, provided the original work is properly cited.

\begin{abstract}
Significant consequences result when a microgrid is connected to a distribution system. This study discusses the impacts of bolted three-phase faults and bolted single line-to-ground faults on the protection coordination of a distribution system connected by a microgrid which operates in utility-only mode or in grid-connected mode. The power system simulation software is used to build the test system. The linear programming method is applied to optimize the coordination of relays, and the relays coordination simulation software is used to verify if the coordination time intervals (CTIs) of the primary/backup relay pairs are adequate. In addition, this study also proposes a relays protection coordination strategy when the microgrid operates in islanding mode during a utility power outage. Because conventional $\mathrm{CO} / \mathrm{LCO}$ relays are not capable of detecting high impedance fault, intelligent electrical device (IED) combined with wavelet transformer and neural network is proposed to accurately detect high impedance fault and identify the fault phase.
\end{abstract}

\section{Introduction}

Because of the energy crisis caused by the decrease of oil reserve, the global warming and climate change caused by the greenhouse effect, and the air pollution caused by fossil fuel consumption, development of clean and pollutionfree energy has become an important global issue. The energy policies to develop and utilize renewable distributed resources such as the wind generation, tidal wave generation, and photovoltaic generation are widely formed by countries around the world [1, 2]. The IEEE 1547 [3] standard for the operations of the distributed resources and the electric power system requires that the distributed resources be disconnected from the electric power system when there is a fault in the electric power system. Such requirement not only limits the development of distributed resources seriously but also affects the power quality and stability of power systems.

This problem can be solved by the microgrid structure. A microgrid structure is a small generation/distribution system which consists of distributed resources, energy storage systems (ESSs) [4], energy conversion devices, load monitoring and control devices, and protection devices. The microgrid can be connected to electric power system and can reduce feeder line losses, stabilize local voltage, and increase local reliability. The microgrid is an intelligent system that can control, manage, and protect itself.

This study focuses on the problems of protection coordination resulting from the changes of system structure by the connection of the distribution system and the microgrid, such as insufficient interruption capacity of circuit breakers due to the increase of fault currents and the disoperation of relays due to changes of fault current directions. The magnitude and direction of each fault current after the interconnection must be reexamined and the relays settings and the circuit breakers interrupting capacities must be reconfigured after the microgrid is connected to the system. This study uses the power system simulation software to build a test system which includes a normally open loop distribution system and three microgrids to simulate bolted three-phase faults and bolted single line-to-ground faults in a distribution system both in utility-only mode and in grid-connected mode. In the grid-connected mode, electric power is supplied to the system both by the utility system and by the microsources of microgrid through the grid-connection controller. In 
the utility-only mode, the microsources of microgrid do not supply electric power to the system due to failure or maintenance. The linear programming method is adopted to optimize the relay coordination. Furthermore, because the microgrid enters islanding mode when a fault occurs in the utility system and the protection coordination mechanism in islanding mode is different from those in conventional utilityonly and grid-connected mode, the protection coordination mechanism of the microgrid in islanding mode must also be reexamined [5].

\section{Microsource and Power System Protection}

2.1. Wind Generation. Wind generation is used as the microsource of the microgrid in this study. The model of the wind generation is shown in Figure 1. The wind is generated by the wind source mean and is inputted to the wind turbine, and the electric generator is driven by the mechanical output from the wind turbine to generate electric power. The pitch angle of the wind turbine is controlled by the wind turbine governor. The parameters of the electric generator are shown in Table 1.

In this study, the parameters of the wind turbine are as follows. The electrical power output is

$$
P_{e}=\frac{1}{2} C_{p} \eta_{g} \eta_{t} \rho A V^{3}=2700 \mathrm{~kW}
$$

where the power coefficient of the rotor is

$$
C_{p}=\frac{1}{2}\left(\gamma-0.022 \beta^{2}-5.6\right) e^{-0.17 \gamma}
$$

$\beta$ is ignored and

$$
\gamma=2.237 \frac{V}{\omega}
$$

$V=13 \mathrm{~m} / \mathrm{sec}$ is wind velocity, machine rated angular mechanical speed $\omega=3.77 \mathrm{rad} / \mathrm{s}, \eta_{g}$ is electric generator efficiency, $\eta_{t}$ is transmission efficiency, $\eta_{g} \eta_{t}=0.75, \rho=$ $1.225 \mathrm{~kg} / \mathrm{m}^{3}$ is air density, $A=\pi R^{2}$ is rotor swept area, and $R=54.758 \mathrm{~m}$ is rotor radius.

The wind turbine is assumed to operate at constant speed under both normal and fault conditions. The energy storage system (ESS) stores energy and does not provide fault current in grid-connected mode. The ESS will supply the microgrid's load when the microgrid operates under islanding mode.

2.2. Architecture of Distribution System. The main architecture of the Taipower company underground distribution system is the normally open loop scheme, with feeders forming main trunk loops and lateral loops. The end of a main trunk line is connected to another main trunk line by a normally open tie switch to form a main trunk loop, and the end of a lateral is connected to a lateral of another main trunk loop by a normally open tie switch to form a lateral loop. Such configuration is adopted in the test system built in this study.

Main circuit breaker (Main CB) protection is adopted for the main transformers, feeder circuit breaker (FCB) protection is adopted for the feeders, lateral circuit breaker
TABLE 1: Parameters of the electric generator.

\begin{tabular}{lc}
\hline Parameter & Value \\
\hline Number of pole pairs & 100 \\
Rated speed at $60 \mathrm{~Hz}$ & $3.77 \mathrm{rad} / \mathrm{s}$ \\
Rated capacity $\left(S_{n}\right)$ & $3 \mathrm{MVA}$ \\
Rated voltage $\left(V_{n}\right)$ & $690 \mathrm{~V}$ \\
Xd & $0.4 \mathrm{p} \cdot \mathrm{u}$ \\
Rated current $\left(I_{n}\right)$ & $1450 \mathrm{~A}$ \\
\hline
\end{tabular}

(LCB) protection using 4-way automatic line switches is adopted for the laterals, and either relay or power fuse protection may be adopted at the terminal duty points of high voltage customers. The architecture of a normally open loop distribution system is shown in Figure 2 [6].

2.3. Criteria of Protection Coordination. Protection relays [7] are deployed in a power system quickly isolate the fault and to minimize the isolated area and to protect facilities from damage when a fault occurs in a power system. Overcurrent (CO) relays are used in this study as the protection devices. The CO relays must operate fast enough to isolate the fault areas and the coordination time intervals (CTIs) of the primary/backup relay pairs should be adequate.

According to the IEEE Std C37.112 [8], CO relays are classified as MI (moderately inverse) type, VI (very inverse) type, and EI (extremely inverse) type by their time-current characteristic curves. Equation (4) with certain values of the constants $A, B$, and $p$ is used to represent the characteristics of a specific $\mathrm{CO}$ relay:

$$
T=\operatorname{TDS} \times\left[\frac{A}{\left(I_{\text {input }} / I_{\text {pickup }}\right)^{p}-1}+B\right],
$$

where $T$ is the tripping time in seconds, TDS is the time dial setting, $I_{\text {input }}$ is the current passing through the relay, $I_{\text {pickup }}$ : the pick-up current, and $A, B$, and $p$ are the constants and exponents to provide selected curve characteristics.

The CO relays of EI type and VI type are used in this study. The CTI of a CO relay is generally about $0.2 \sim 0.5 \mathrm{sec}$, which includes $0.08 \mathrm{sec}$ interrupting time of the circuit breaker of the primary relay, $0.1 \mathrm{sec}$ of inertia rotation time of the backup relay, and $0.22 \mathrm{sec}$ of safety margin. As a result, the CTI of a CO relay is generally set to $0.3 \mathrm{sec}$, and different time intervals should be chosen for relays with different characteristics. However, the CTI may be set to $0.2 \mathrm{sec}$ for a digital relay because the $0.1 \mathrm{sec}$ of inertia rotation time of the backup relay can be ignored.

If a power fuse is used as primary protection and a relay is used as back-up protection, the CTI should be $0.3 \mathrm{sec}$. However, the CTI may be reduced to $0.1 \mathrm{sec}$ if the total clearing time of the power fuse is less than $1 \mathrm{sec}$ [6].

\section{Problems Formulation and Simulation Results}

3.1. Test System under Study. The power system simulation software is used in this study to build the test radial distribution system as shown in Figure 3. The utility is connected to 


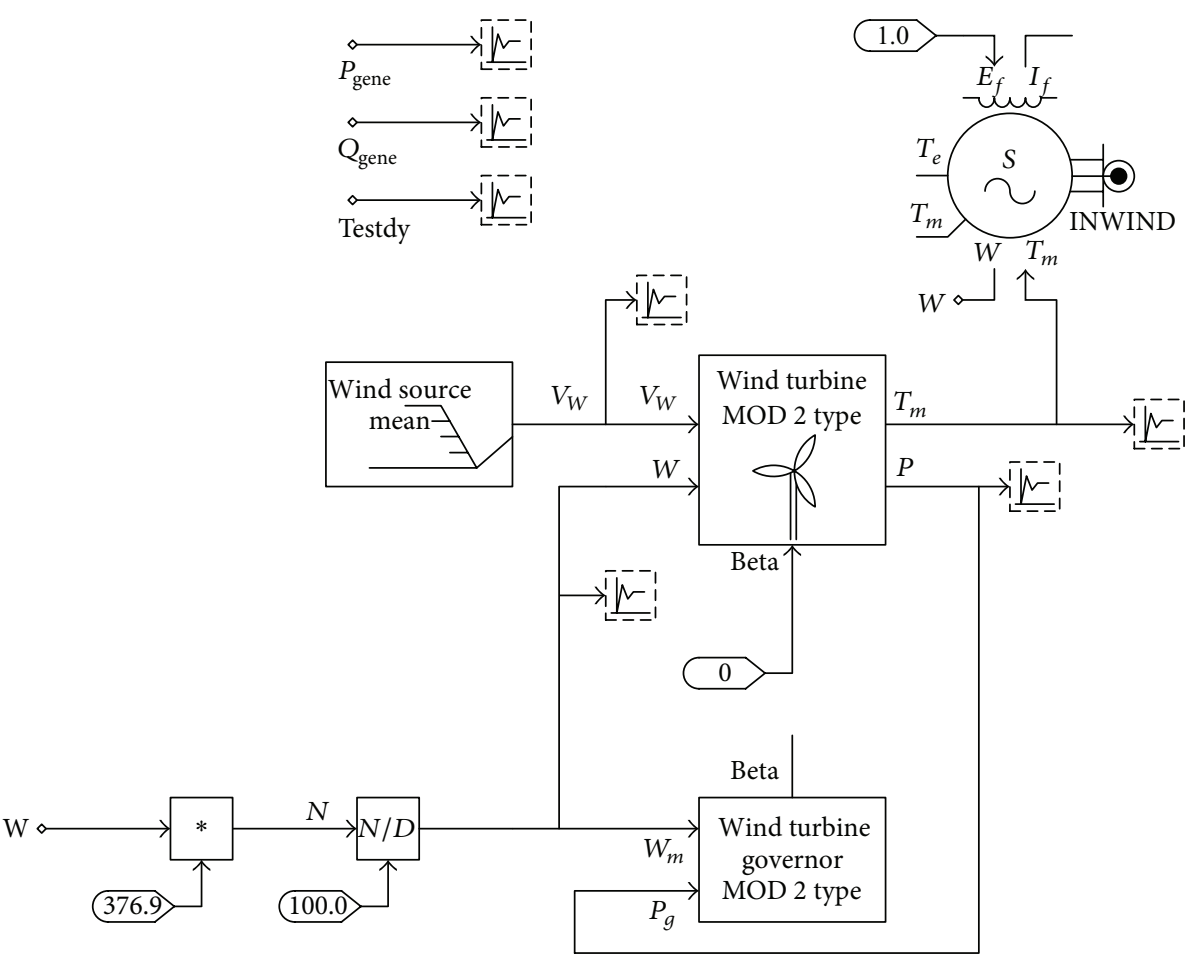

FIGURE 1: The model of the wind generation.

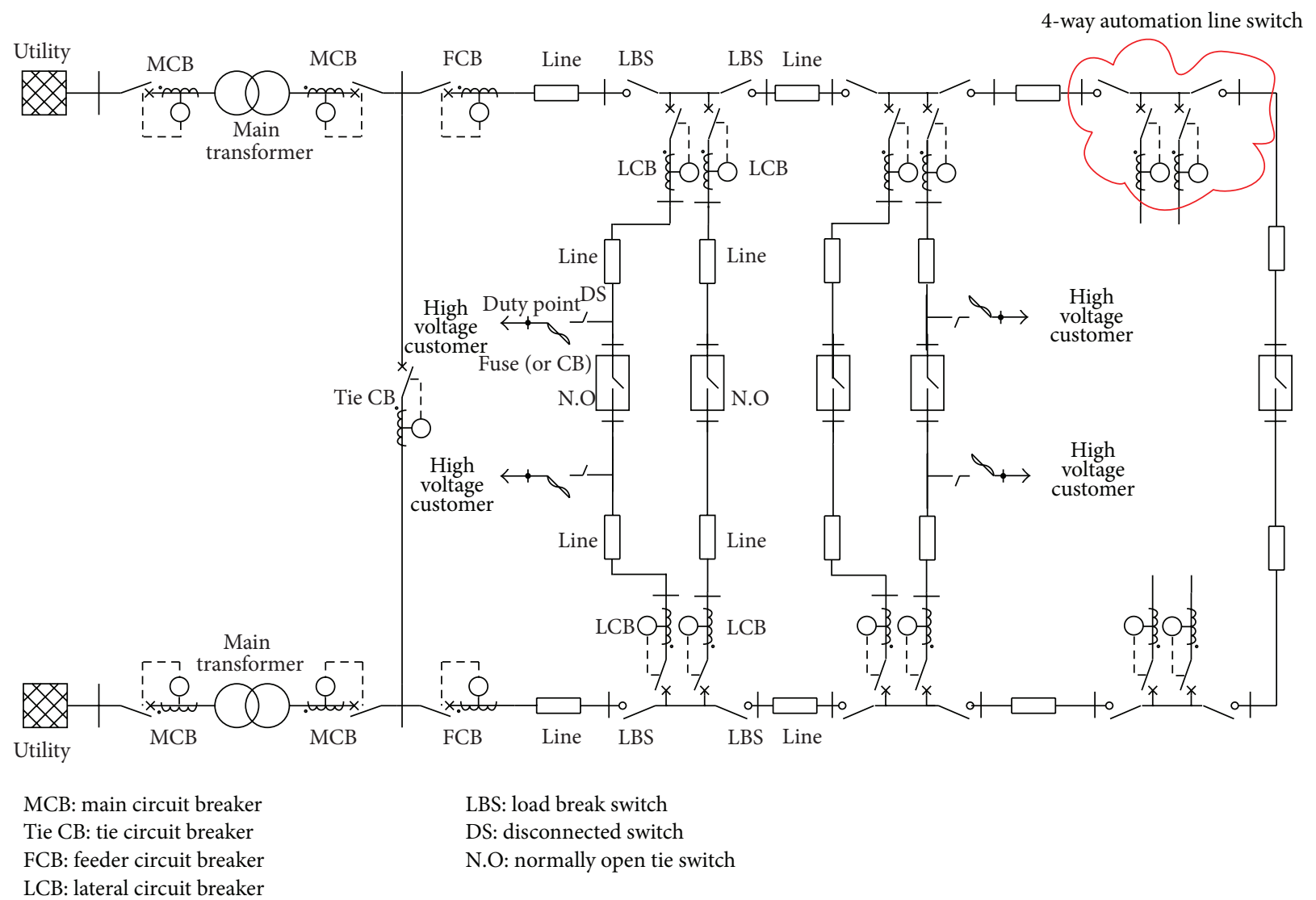

Figure 2: A normally open loop distribution system. 


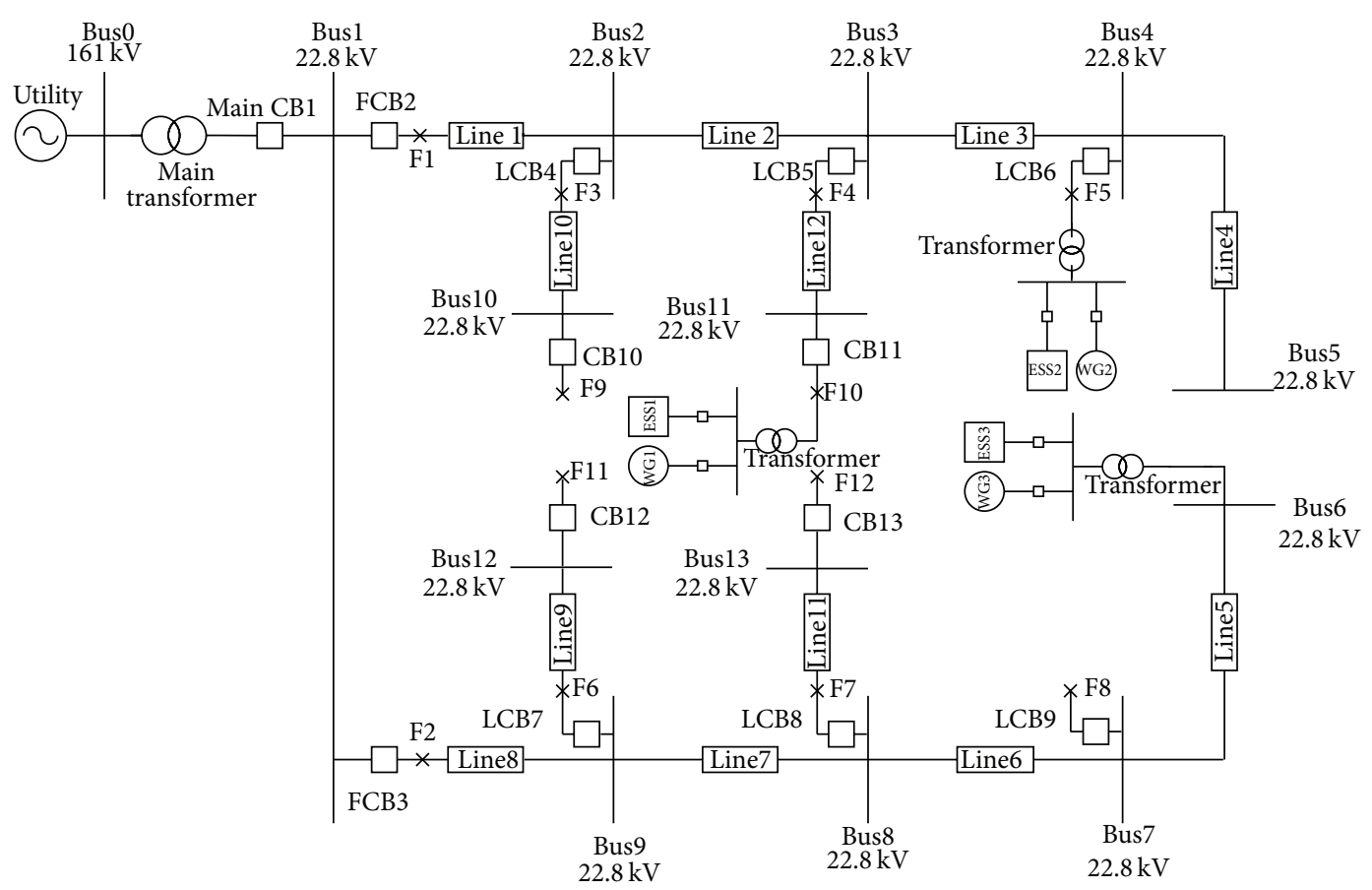

PCC: Point of common coupling

WG: Wind generation

ESS: Energy storage system

FIgURE 3: The test radial distribution system.

the main transformer through Bus0, and the microgrids are connected to Bus4, Bus6, and Bus11. Utility power is delivered through the two feeders Line1-Line4 and Line5-Line8. F1F12 are the near-end faults occurring at the outgoing ends of the feeders, the outgoing ends of the laterals, and the duty points of high voltage customers.

The operation modes of the test system under study are utility-only mode, grid-connected mode, and islanding mode. The operation mode and the system configuration are determined by the switching of the grid-connection controller, and the settings of the protection relays should change according to the operation mode. This study assumes that there are many groups of settings (currently eight groups of settings are available) for the intelligent electrical devices (IEDs) under various operation modes that can be switched using the protection device management system and communication equipment.

3.2. Faults Analysis. The power system simulation software is used in this study to configure the test system which operates in utility-only mode and in grid-connected mode [9]. When a bolted three-phase fault or a bolted single line-to-ground fault occurs, the magnitude and the direction of the fault currents may be utilized to configure the primary/backup relay pairs and to determine the optimal relays settings. Note that, in grid-connected mode, the directions of the fault currents provided by the microsource may be in the same or opposite directions to the corresponding fault currents provided by the utility; thus the total fault currents may be either larger or less than those provided by the utility alone, depending on the location of the microsource. The fault currents at various fault locations are listed in Tables 2 and 3.

3.3. Optimal Coordination of the CO Relays. In order to isolate the fault area as quick as possible, the relays should operate as fast as possible and the primary and back-up protection relay pairs must be well coordinated. This study adopts the linear programming method to find the optimal relay TDSs for optimal relay operating times [10].

The linear programming method is a mathematical mean to achieve the optimal goal by maximizing or minimizing the value of the objective function under certain constraints. In this study, the objective function to be minimized is the sum of the operating times of all the primary relays, and the constraints are that the TDS of every relay must be within its limits and that the CTI of each primary/back-up protection relay pair must be larger than or equal to $0.2 \mathrm{sec}$. For example, for bolted three-phase faults under the utility-only mode, the objective function and the constraints are as shown below.

Objective Function. Consider

$$
\begin{aligned}
\text { Minimize } F(I)= & T_{\text {MainCB1 }}+T_{\mathrm{FCB} 2}+T_{\mathrm{FCB} 3}+T_{\mathrm{LCB} 4} \\
& +T_{\mathrm{LCB} 5}+T_{\mathrm{LCB} 6}+T_{\mathrm{LCB} 7} \\
& +T_{\mathrm{LCB} 8}+T_{\mathrm{LCB} 9}+T_{\mathrm{CB} 10}+T_{\mathrm{CB} 11} \\
& +T_{\mathrm{CB} 12}+T_{\mathrm{CB} 13} .
\end{aligned}
$$


TABLE 2: Fault currents of bolted three-phase faults in utility-only mode and in grid-connected mode.

\begin{tabular}{|c|c|c|c|c|c|c|}
\hline \multirow[t]{2}{*}{ Location of fault } & \multicolumn{2}{|c|}{ Relay } & \multicolumn{2}{|c|}{$\begin{array}{c}\text { Fault current (A) } \\
\text { (utility-only mode) }\end{array}$} & \multicolumn{2}{|c|}{$\begin{array}{c}\text { Fault current }(\mathrm{A}) \\
\text { (grid-connected mode) }\end{array}$} \\
\hline & Primary & Backup & Primary & Backup & Primary & Backup \\
\hline F1 & FCB2 & Main CB1 & 11,687 & 11,687 & 12,104 & 12,048 \\
\hline $\mathrm{F} 2$ & FCB3 & Main CB1 & 11,687 & 11,687 & 12,123 & 12,086 \\
\hline F3 & LCB4 & FCB2 & 7,608 & 7,603 & 7,321 & 7,305 \\
\hline $\mathrm{F} 4$ & LCB5 & FCB2 & 5,612 & 5,588 & 5,593 & 5,300 \\
\hline F5 & LCB6 & FCB2 & 4,446 & 4,399 & 3,886 & 4,231 \\
\hline F6 & LCB7 & FCB3 & 7,608 & 7,603 & 7,228 & 7,016 \\
\hline F7 & LCB8 & FCB3 & 5,612 & 5,588 & 5,298 & 5,075 \\
\hline F8 & LCB9 & FCB3 & 4,446 & 4,399 & 4,208 & 3,938 \\
\hline F9 & CB10 & LCB4 & 5,672 & 5,668 & 4,737 & 4,731 \\
\hline F10 & CB11 & LCB5 & 4,483 & 4,480 & 3,881 & 3,882 \\
\hline F11 & $\mathrm{CB} 12$ & LCB7 & 5,672 & 5,668 & 4,826 & 4,823 \\
\hline F12 & $\mathrm{CB} 13$ & LCB8 & 4,483 & 4,480 & 3,706 & 3,706 \\
\hline
\end{tabular}

TABLE 3: Fault currents of bolted single line-to-ground faults in utility-only mode and in grid-connected mode.

\begin{tabular}{|c|c|c|c|c|c|c|}
\hline \multirow[t]{2}{*}{ Location of fault } & \multicolumn{2}{|c|}{ Relay } & \multicolumn{2}{|c|}{$\begin{array}{c}\text { Fault current (A) } \\
\text { (utility-only mode) }\end{array}$} & \multicolumn{2}{|c|}{$\begin{array}{c}\text { Fault current (A) } \\
\text { (grid-connected mode) }\end{array}$} \\
\hline & Primary & Backup & Primary & Backup & Primary & Backup \\
\hline F1 & FCB2 & Main CB1 & 12,016 & 12,006 & 11,696 & 11,947 \\
\hline F2 & FCB3 & Main CB1 & 12,016 & 12,006 & 11,432 & 11,946 \\
\hline F3 & LCB4 & FCB2 & 7,270 & 7,256 & 6,450 & 6,885 \\
\hline $\mathrm{F} 4$ & LCB5 & FCB2 & 5,072 & 5,042 & 4,537 & 4,753 \\
\hline F5 & LCB6 & FCB2 & 3,854 & 3,826 & 3,389 & 3,697 \\
\hline F6 & LCB7 & FCB3 & 7,270 & 7,256 & 6,333 & 6,630 \\
\hline F7 & LCB8 & FCB3 & 5,072 & 5,042 & 4,229 & 4,518 \\
\hline F8 & LCB9 & FCB3 & 3,876 & 3,826 & 3,131 & 3,403 \\
\hline F9 & $\mathrm{CB} 10$ & LCB4 & 5,241 & 5,236 & 4,348 & 4,346 \\
\hline F10 & CB11 & LCB5 & 3,986 & 3,981 & 3,449 & 3,442 \\
\hline F11 & $\mathrm{CB} 12$ & LCB7 & 5,241 & 5,235 & 4,340 & 4,338 \\
\hline F12 & CB13 & LCB8 & 3,986 & 3,981 & 3,188 & 3,187 \\
\hline
\end{tabular}

Constraints. We have

$$
\begin{gathered}
T_{\text {MainCB1 }}-T_{\mathrm{FCB} 2} \geq 0.2, \\
T_{\mathrm{FCB} 2}-T_{\mathrm{LCB} 4} \geq 0.2, \\
T_{\mathrm{FCB} 2}-T_{\mathrm{LCB} 5} \geq 0.2, \\
T_{\mathrm{FCB} 2}-T_{\mathrm{LCB} 6} \geq 0.2, \\
T_{\text {MainCB1 }}-T_{\mathrm{FCB} 3} \geq 0.2, \\
T_{\mathrm{FCB} 3}-T_{\mathrm{LCB} 7} \geq 0.2, \\
T_{\mathrm{FCB} 3}-T_{\mathrm{LCB} 8} \geq 0.2, \\
T_{\mathrm{FCB} 3}-T_{\mathrm{LCB} 9} \geq 0.2, \\
T_{\mathrm{LCB} 4}-T_{\mathrm{CB} 10} \geq 0.2, \\
T_{\mathrm{LCB} 5}-T_{\mathrm{LCB} 11} \geq 0.2, \\
T_{\mathrm{LCB} 7}-T_{\mathrm{CB} 12} \geq 0.2, \\
T_{\mathrm{LCB} 8}-T_{\mathrm{CB} 13} \geq 0.2 .
\end{gathered}
$$

Considering the magnitudes of the fault currents and the relay characteristics curves, the above equations can be modified as follows.
Objective Function. Consider

$$
\begin{aligned}
\text { Minimize } F(I)= & 0.97246 \times \mathrm{TDS}_{\mathrm{MainCB} 1} \\
& +0.19622 \times \mathrm{TDS}_{\mathrm{FCB} 2} \\
& +0.19622 \times \mathrm{TDS}_{\mathrm{FCB} 3} \\
& +0.19228 \times \mathrm{TDS}_{\mathrm{LCB} 4} \\
& +0.25159 \times \mathrm{TDS}_{\mathrm{LCB} 5} \\
& +0.32922 \times \mathrm{TDS}_{\mathrm{LCB} 6} \\
& +0.19222 \times \mathrm{TDS}_{\mathrm{LCB} 7} \\
& +0.25159 \times \mathrm{TDS}_{\mathrm{LCB} 8} \\
& +0.32922 \times \mathrm{TDS}_{\mathrm{LCB} 9} \\
& +0.14705 \times \mathrm{TDS}_{\mathrm{CB} 10} \\
& +0.16231 \times \mathrm{TDS}_{\mathrm{CB} 11} \\
& +0.14705 \times \mathrm{TDS}_{\mathrm{CB} 12} \\
& +0.16231 \times \mathrm{TDS}_{\mathrm{CB} 13} .
\end{aligned}
$$


Current (amps) ×10@22800 volts

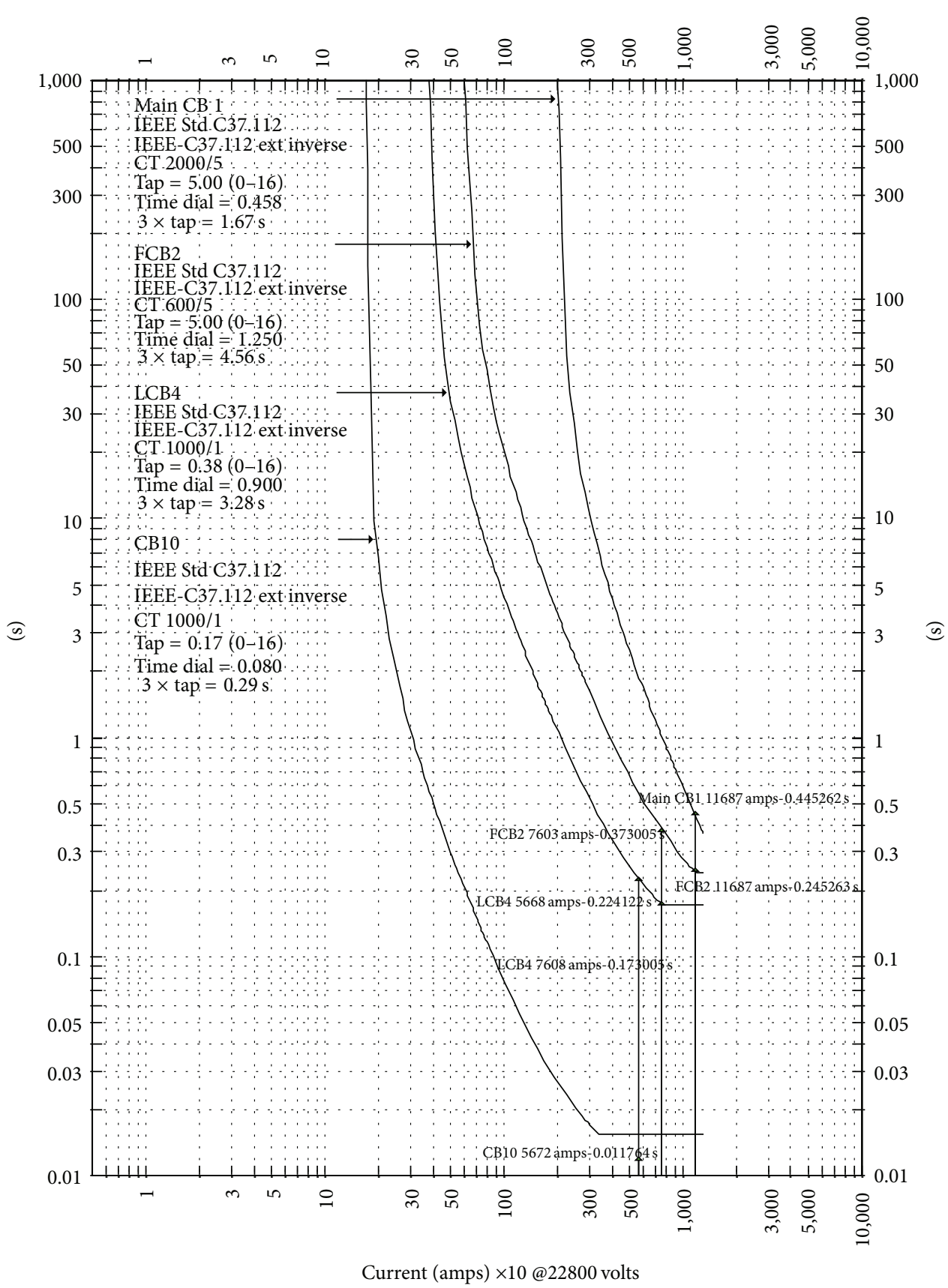

FIGURE 4: The time-current characteristic curves of Main CB1, FCB2, LCB4, and CB10 for a bolted three-phase fault in utility-only mode.

\section{Constraints. We have}

$$
\begin{gathered}
0.97246 \times \mathrm{TDS}_{\mathrm{MainCB} 1}-0.19622 \times \mathrm{TDS}_{\mathrm{FCB} 2} \geq 0.2, \\
0.29842 \times \mathrm{TDS}_{\mathrm{FCB} 2}-0.19228 \times \mathrm{TDS}_{\mathrm{LCB} 4} \geq 0.2, \\
0.45060 \times \mathrm{TDS}_{\mathrm{FCB} 2}-0.25159 \times \mathrm{TDS}_{\mathrm{LCB} 5} \geq 0.2, \\
0.65626 \times \mathrm{TDS}_{\mathrm{FCB} 2}-0.32922 \times \mathrm{TDS}_{\mathrm{LCB} 6} \geq 0.2, \\
0.97246 \times \mathrm{TDS}_{\mathrm{MainCB} 1}-0.19622 \times \mathrm{TDS}_{\mathrm{FCB} 3} \geq 0.2, \\
0.29842 \times \mathrm{TDS}_{\mathrm{FCB} 3}-0.19222 \times \mathrm{TDS}_{\mathrm{LCB} 7} \geq 0.2,
\end{gathered}
$$

$$
\begin{gathered}
0.45060 \times \mathrm{TDS}_{\mathrm{FCB} 3}-0.25159 \times \mathrm{TDS}_{\mathrm{LCB} 8} \geq 0.2, \\
0.65626 \times \mathrm{TDS}_{\mathrm{FCB} 3}-0.32922 \times \mathrm{TDS}_{\mathrm{LCB} 9} \geq 0.2, \\
0.24902 \times \mathrm{TDS}_{\mathrm{LCB} 4}-0.14705 \times \mathrm{TDS}_{\mathrm{CB} 10} \geq 0.2, \\
0.32606 \times \mathrm{TDS}_{\mathrm{LCB} 5}-0.16231 \times \mathrm{TDS}_{\mathrm{LCB} 11} \geq 0.2, \\
0.24902 \times \mathrm{TDS}_{\mathrm{LCB} 7}-0.14705 \times \mathrm{TDS}_{\mathrm{CB} 12} \geq 0.2, \\
0.32606 \times \mathrm{TDS}_{\mathrm{LCB} 8}-0.16231 \times \mathrm{TDS}_{\mathrm{CB} 13} \geq 0.2, \\
0.08 \leq \mathrm{TDS}_{i} \leq 2,
\end{gathered}
$$




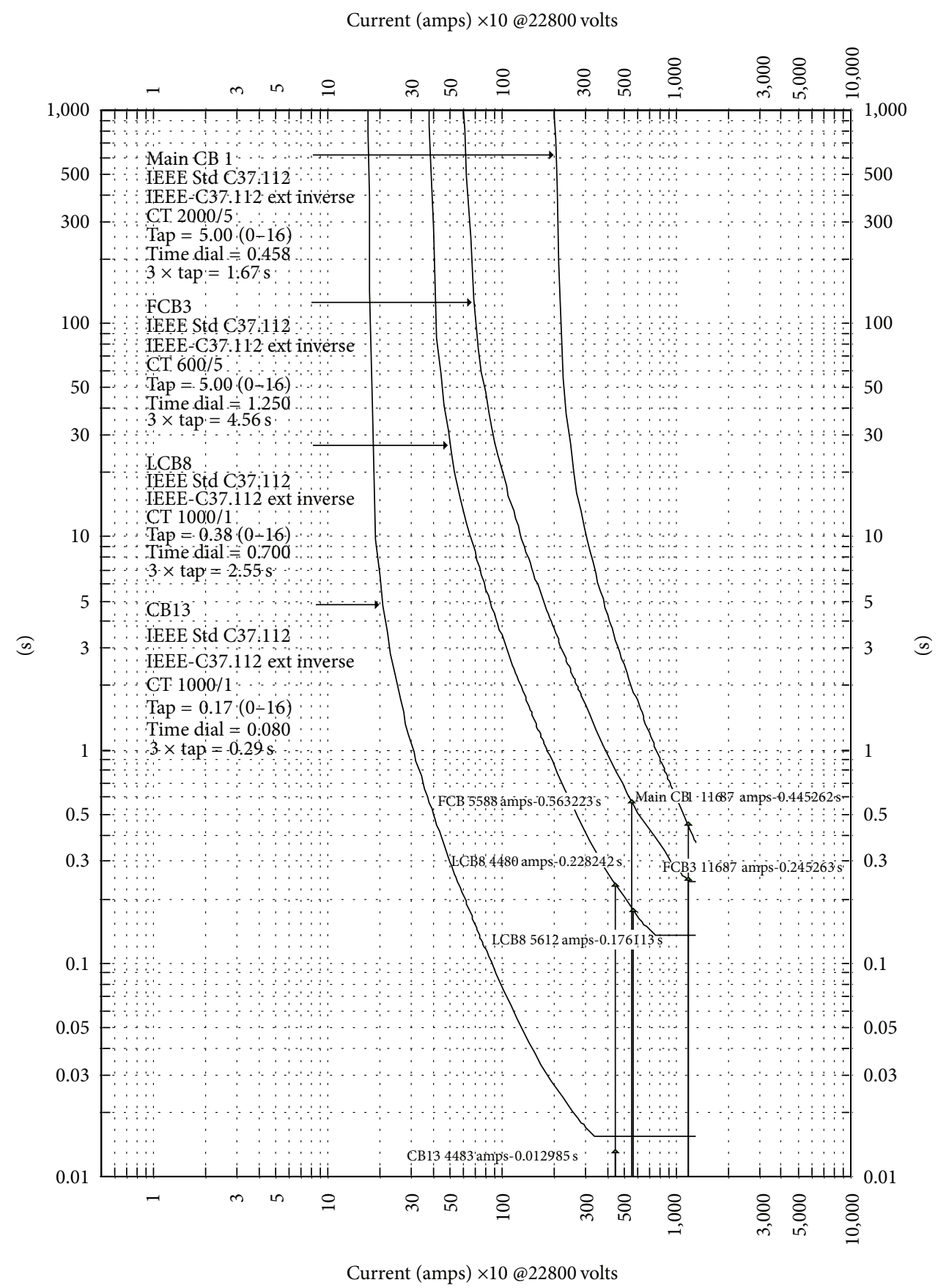

FIGURE 5: The time-current characteristic curves of Main CB1, FCB3, LCB8, and CB13 for a bolted three-phase fault in utility-only mode.

where $i=$ [Main CB1, FCB2, FCB3, LCB4, LCB5, LCB6, LCB7, LCB8, LCB9, CB10, CB11, CB12, CB13].

The optimal TDSs of the CO relays found in utilityonly mode and in grid-connected mode are listed in Table 4. The operating times and the CTIs of the primary/back-up protection relay pairs are also listed in Table 5 to verify the optimization result.

The relays coordination simulation software is used in this study to plot the time-current characteristic curves of the primary/backup relay pairs shown in Figures 4 and 5 for a bolted three-phase fault in utility-only mode. Except for the operating times of $\mathrm{CB} 10, \mathrm{CB} 11, \mathrm{CB} 12$, and $\mathrm{CB} 13$ at the duty points of high voltage customers which need to be adjusted for protection coordination, Main CB, FCB2, FCB3, LCB4-9 and all relays meet the operating time requirements.

Because the relay operating times of $\mathrm{CB} 10-\mathrm{CB} 13$ are fixed at $0.015 \mathrm{sec}$ for fault currents larger than $3423 \mathrm{~A}$, the corresponding relays operating times of CB10-CB13 in Table 5 are corrected to be $0.015 \mathrm{sec}$ as well, and all the CTIs between CB10-CB13 relays and their corresponding back-up relays after modification are checked and verified to be larger than $0.2 \mathrm{sec}$ as listed in Table 5. The results of the optimal 
Current (amps) ×10@22800 volts

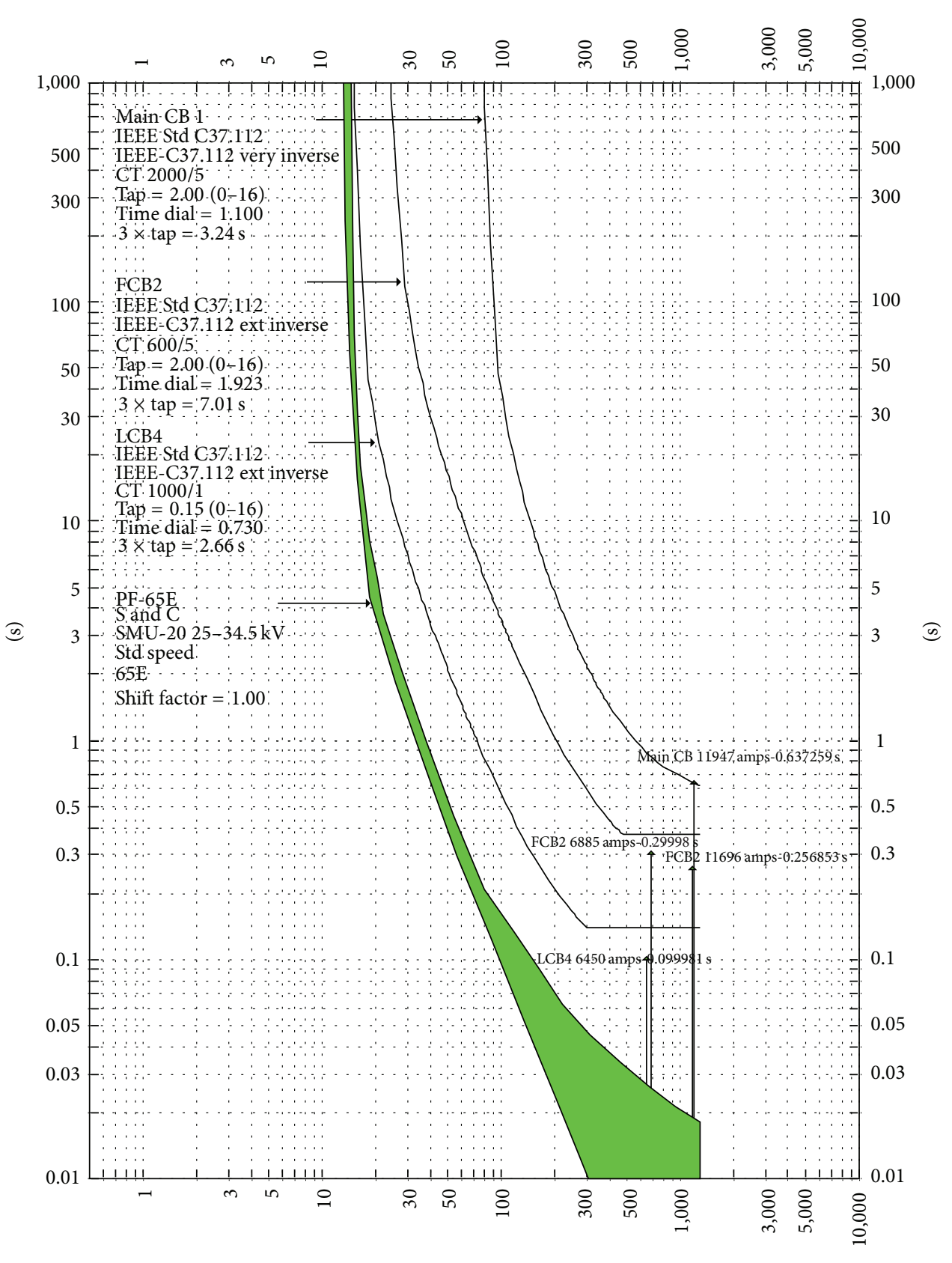

Current (amps) $\times 10 @ 22800$ volts

FIgURE 6: The time-current characteristic curves of Main CB1, FCB2, LCB4, and PF-65E for a bolted single line-to-ground fault in gridconnected mode.

coordination in grid-connected mode are also shown in Table 5.

3.4. Optimal Protection Coordination of Low-Energy Overcurrent (LCO) Relays. Because the magnitudes of the fault currents of a bolted single line-to-ground fault are generally less than those of a bolted three-phase fault, a power fuse is often used as primary protection device at the duty point of a high voltage customer. The optimal TDSs of the LCO relays for protection coordination for bolted single line-to-ground faults in utility-only mode and in grid-connected mode are listed in Table 6. The operation times and the CTIs of all primary/backup relay pairs are listed in Table 7.

The relay time-current characteristic curves for bolted single line-to-ground faults in grid-connected mode are shown in Figures 6 and 7, where the PF-65E power fuses and the LCBs are in coordination with each other for the CTIs that are all larger than $0.1 \mathrm{sec}$. Note that errors exist between the actual operating times of FCBs and LCBs and those computed by the linear programming method because 


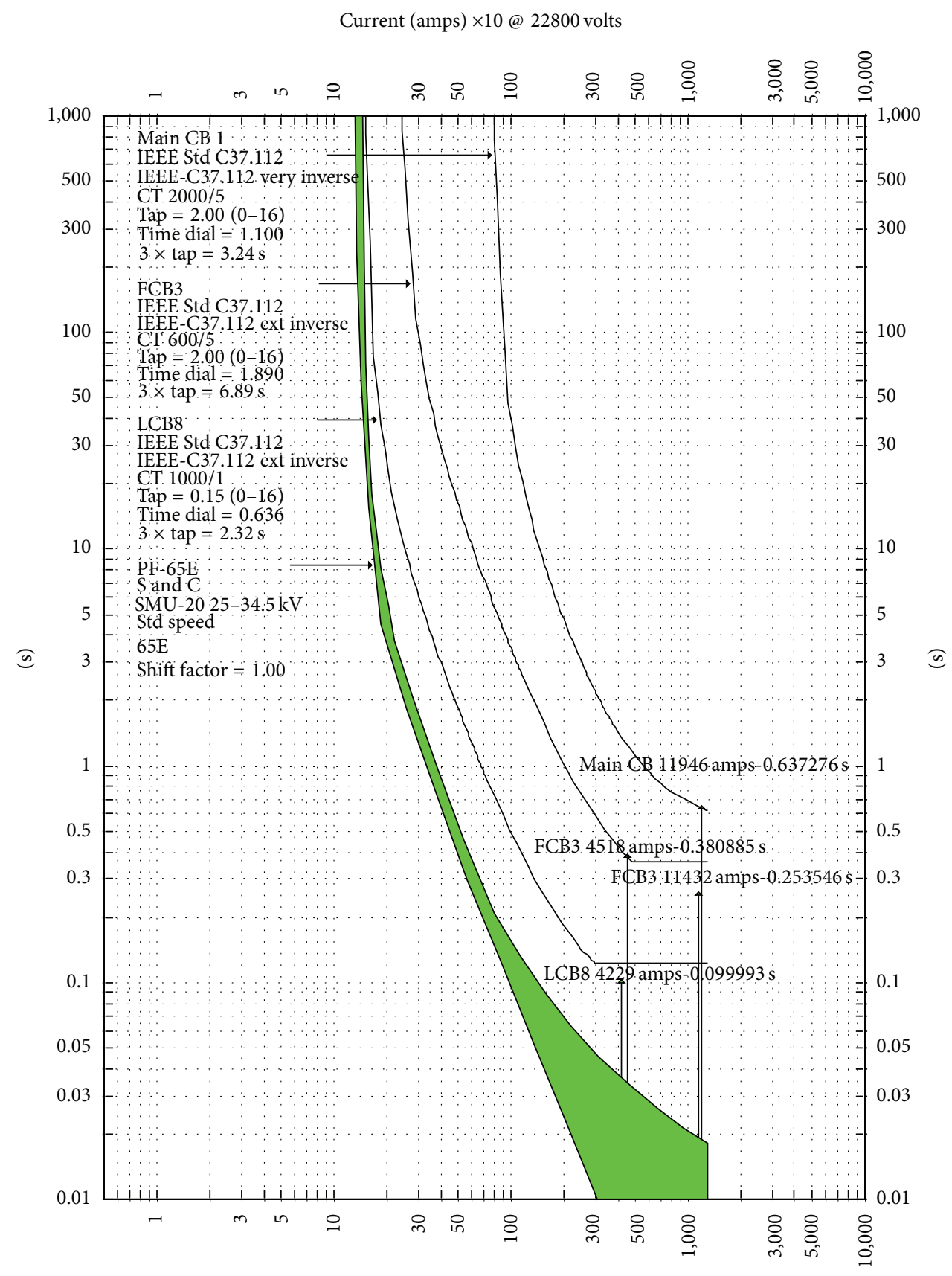

Current (amps) ×10@22800 volts

FIGURE 7: The time-current characteristic curves of Main CB1, FCB3, LCB8, and PF-65E for a bolted single line-to-ground fault in gridconnected mode.

the actual operating time of a relay is fixed at a constant value when the fault current is equal to or greater than the upper threshold. Therefore the erroneous relay operating times must be corrected to achieve optimal protection coordination. Such corrections are also made for the relay operating times in utility-only mode, and the results are also listed in Table 7 .

The relay settings obtained from optimization processes were generally taken to be the final optimal results in previous literatures. However, as shown in this study, the results must be checked by plotting actual time-current characteristic curves and by more detailed examinations to determine if the results are optimal or if further corrections are needed.

\section{Proposed Protection Strategy for Islanding}

When a fault occurs in the utility, the microgrid will be disconnected from the utility and operate in islanding mode. Under such circumstance, the power to the test system under study is provided by the ESSs at Bus4, Bus6, and Bus11, 

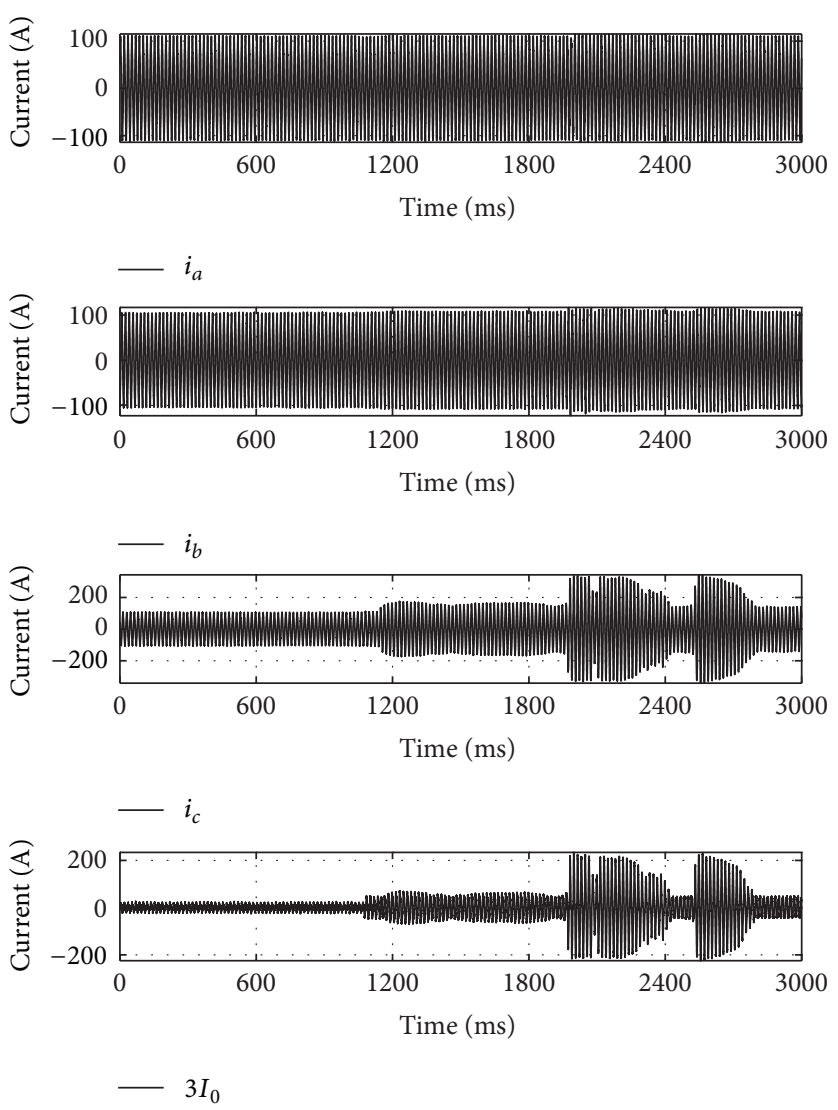

FIGURE 8: The three phase currents and the $3 I_{0}$ zero-sequence current of the c-phase bare copper power line falling on concrete pavement.

whose capacities are the same as the wind generations as shown in Figure 3. Power electronic technique is generally applied to limit the fault current that can be supplied by the microsource to about 1.5 2 times its rated output current. This study chooses 1.5 times the rated output current to be the fault current that the ESSs can supply during fault period and assumes that at least two ESSs are supplying electric power simultaneously in islanding mode to maintain high power supply reliability. Therefore the test system under study may operate in any of the four sub-modes because there are three ESSs in the system. The fault currents in the sub-mode with three ESSs supplying electric power simultaneously are calculated and listed in Table 8.

This study proposes a protection coordination strategy that not only utilizes a protection device management system to integrate the protection coordination strategies of the entire system but also uses IEDs that conform to the IEC61850 [11-14] communication protocol as protection devices under the islanding mode. Power fuses are not suitable protection devices because IEC61850 GOOSE communication capability is required for protection equipment. IEDs must be able to determine the direction of the fault current and must multiply groups of trip settings. For example, an IED in this study system will issue the trip signal only when there is a forward fault and when the fault current is larger than the pickup value $I_{p}$. The operating curves of the IEDs are set for definite time and proper pick-up values for each IED can be chosen and set by the protection device management system according to the submode in which the system operates. The pickup value $I_{p}$ of an IED is set to $80 \%$ of maximum fault current to take into consideration the energy drain in ESSs caused by the load demand. The TDS values of all IEDs are set to 2, which means the trip signal will be issued 2 cycles after a fault is detected. The Taps and TDSs for all IEDs in islanding mode are listed in Table 9.

The FCBs of the same main transformer are interlinked by GOOSE messaging [15-18], and so are the LCBs of the same feeder and all the CBs of the ESSs. A feeder fault at F2 and a lateral fault at F6 are discussed below as examples.

\section{(i) A Feeder Fault at F2.}

(1) FCB3 immediately issues a CB trip signal when it detects the fault. FCB2, which is interlinked with FCB3 through GOOSE messaging, is checked and will trip if the current flowing through FCB2 increases abnormally.

(2) Check the current of the nearest ESS and trip the CB to this ESS if the current increases abnormally. Then check the current of the nextto-nearest ESS and trip the CB to this ESS if the load-nonrelated part of the current increases abnormally, and so on until the fault is cleared. The nearness of ESS is defined by the number 

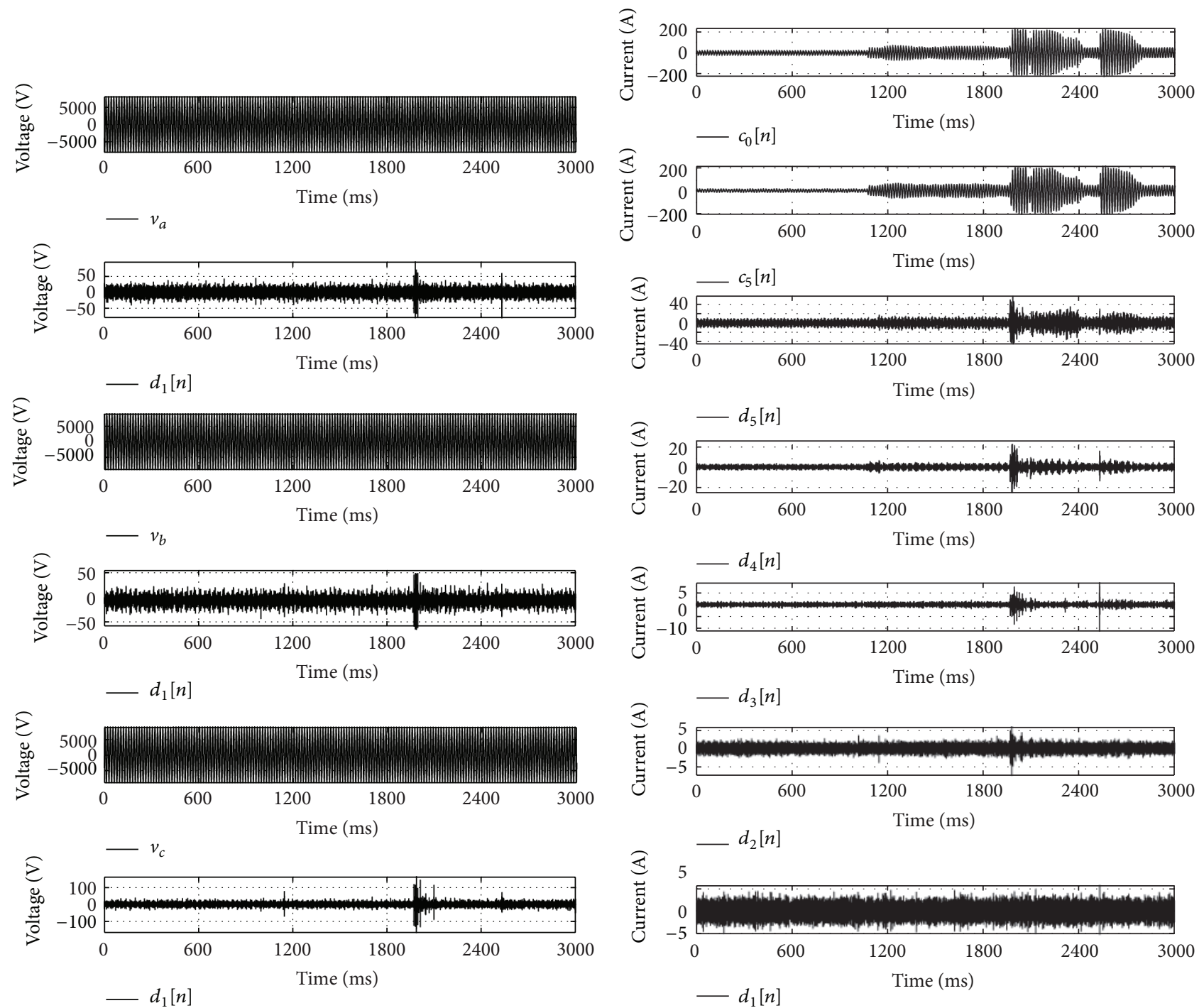

(a)

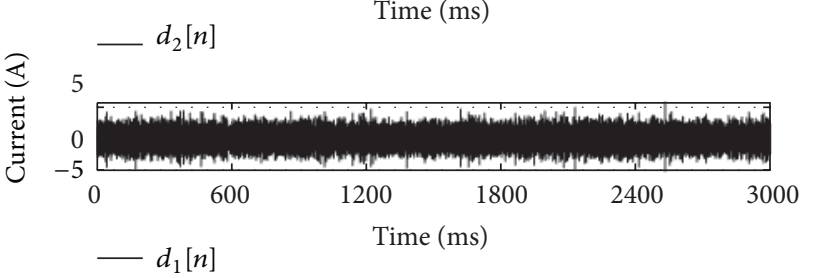

(b)

FIGURE 9: Waveforms of a c-phase bare copper power line falling on concrete pavement: (a) three-phase voltages and the $d_{1}[n]$ wavelet coefficients and (b) $3 I_{0}$ zero-sequence current and the 5-level wavelet decomposition.

of IEDs the ESS current flows through before it reaches the fault; the lesser the nearer.

\section{(ii) A Lateral Fault at F6.}

(1) LCB7 trips. LCB8 and LCB9 are interlinked with LCB7 through GOOSE messaging. The CBs of LCB8 and LCB9 will trip if the currents of LCB8 and LCB9 increase abnormally. Check if there is an ESS connected to the faulty lateral. If so, the $\mathrm{CB}$ to the ESS must trip immediately.

(2) FCB3, to which the feeder of LCB7 is connected to, is checked and will trip its $\mathrm{CB}$ if its current increases abnormally. FCB2, which is interlinked to FCB3, will also trip if the fault is not cleared.
(3) Check the current of the nearest ESS and trip the CB to this ESS if the current increases abnormally. Then check the current of the nextto-nearest ESS and trip the CB to this ESS if the load-nonrelated part of the current increases abnormally, and so on until the fault is cleared.

In summary, although a fault must be isolated as quick as possible, ESSs should remain connected if possible to increase the reliability of the power utility.

\section{Detection of High Impedance Fault}

When an overhead power line breaks and falls to the ground, the fault current is small and is usually less than $100 \mathrm{~A}$ because the voltage of a distribution system is relatively low and the impedance of the ground is high. A high impedance fault 
TABLE 4: Optimal TDSs of the CO relays.

\begin{tabular}{lcccc}
\hline Relay & CT ratio & Tap & Utility-only mode & TDS \\
\hline Main CB1 & & 5.0 & 0.458 & 0.451 \\
FCB2 & $2000 / 5$ & 5.0 & 1.250 & 1.125 \\
FCB3 & $600 / 5$ & 5.0 & 1.250 & 1.074 \\
LCB4 & $600 / 5$ & 0.38 & 0.900 & 0.770 \\
LCB5 & $1000 / 1$ & 0.38 & 0.700 & 0.600 \\
LCB6 & $1000 / 1$ & 0.38 & 0.080 & 0.080 \\
LCB7 & $1000 / 1$ & 0.38 & 0.900 & 0.770 \\
LCB8 & $1000 / 1$ & 0.38 & 0.700 & 0.509 \\
LCB9 & $1000 / 1$ & 0.38 & 0.080 & 0.080 \\
CB10 & $1000 / 1$ & 0.17 & 0.080 & 0.080 \\
CB11 & $1000 / 1$ & 0.17 & 0.080 & 0.080 \\
CB12 & $1000 / 1$ & 0.17 & 0.080 \\
CB13 & $1000 / 1$ & 0.17 & 0.080 & 0.080 \\
\hline
\end{tabular}

TABLE 5: Relay operating times for bolted three-phase faults in utility-only mode and in grid-connected mode.

\begin{tabular}{|c|c|c|c|c|c|c|c|}
\hline \multirow{3}{*}{ Primary relay } & \multirow{3}{*}{ Back-up relay } & \multicolumn{6}{|c|}{ Operating time (sec) } \\
\hline & & \multicolumn{3}{|c|}{ Utility-only mode } & \multicolumn{3}{|c|}{ Grid-connected mode } \\
\hline & & Primary & Backup & CTI & Primary & Backup & CTI \\
\hline FCB2 & Main CB1 & 0.245 & 0.445 & 0.2 & 0.215 & 0.415 & 0.2 \\
\hline FCB3 & Main CB1 & 0.245 & 0.445 & 0.2 & 0.205 & 0.413 & 0.208 \\
\hline LCB4 & FCB2 & 0.173 & 0.373 & 0.2 & 0.152 & 0.352 & 0.2 \\
\hline LCB5 & FCB2 & 0.176 & 0.563 & 0.387 & 0.151 & 0.548 & 0.397 \\
\hline LCB6 & FCB2 & 0.026 & 0.820 & 0.794 & 0.031 & 0.787 & 0.756 \\
\hline LCB7 & FCB3 & 0.173 & 0.373 & 0.2 & 0.153 & 0.353 & 0.2 \\
\hline LCB8 & FCB3 & 0.176 & 0.563 & 0.387 & 0.136 & 0.560 & 0.424 \\
\hline LCB9 & FCB3 & 0.026 & 0.820 & 0.794 & 0.028 & 0.850 & 0.822 \\
\hline CB10 & LCB4 & $0.011(0.015)^{*}$ & 0.224 & $0.213(0.209)$ & $0.012(0.015)$ & 0.234 & $0.222(0.219)$ \\
\hline CB11 & LCB5 & $0.012(0.015)$ & 0.228 & $0.216(0.213)$ & $0.014(0.015)$ & 0.236 & $0.222(0.221)$ \\
\hline CB12 & LCB7 & $0.011(0.015)$ & 0.224 & $0.213(0.209)$ & $0.012(0.015)$ & 0.229 & $0.217(0.214)$ \\
\hline $\mathrm{CB} 13$ & LCB8 & $0.012(0.015)$ & 0.228 & $0.216(0.213)$ & $0.014(0.015)$ & 0.215 & $0.201(0.200)$ \\
\hline
\end{tabular}

${ }^{*}$ The corrected values are shown in parentheses.

TABLE 6: Optimal TDSs of the LCO relays.

\begin{tabular}{lcccc}
\hline Relay & CT ratio & Tap & Utility-only mode & TDS \\
\hline Main CB1 & & 2.0 & 1.100 & 1.100 \\
FCB2 & $2000 / 5$ & 2.0 & 1.968 & 1.923 \\
FCB3 & $600 / 5$ & 2.0 & 1.968 & 1.890 \\
LCB4 & $600 / 5$ & 0.15 & 0.750 & 0.730 \\
LCB5 & $1000 / 1$ & 0.15 & 0.690 & 0.655 \\
LCB6 & $1000 / 1$ & 0.15 & 0.100 & 0.100 \\
LCB7 & $1000 / 1$ & 0.15 & 0.750 & 0.727 \\
LCB8 & $1000 / 1$ & 0.15 & 0.690 & 0.636 \\
LCB9 & $1000 / 1$ & 0.15 & 0.100 & 0.100 \\
\hline
\end{tabular}

like this is hard to be detected by conventional protection devices such as power fuses or CO/LCO relays because the fault current is low. When a high impedance fault occurs, the charged power line comes in contact with high impedance objects, for example, tar road, concrete pavement, sand, grass, or a tree which is not directly grounded, and high impedance fault arcs are generated. Electric shock and casualty may occur because the power line is still charged, and the arcs may lead to fire and be a threat to public safety or may result in property losses.
The three-phase currents and the $3 I_{0}$ zero-sequence current of the c-phase bare copper power line of an overhead distribution system when it falls on concrete pavement are measured at the location of the responsible FCB and are shown in Figure 8. It can be seen that there are noticeable changes in the c-phase current. At the instant when the power line touches the concrete pavement, no arc is generated yet. But as the air is ionized and insulation breaks down, low impedance electric path between the power line and the concrete pavement is formed and arcs are generated. The 
TABLE 7: Operating times and CTIs for bolted single line-to-ground faults in utility-only mode and in grid-connected mode.

\begin{tabular}{|c|c|c|c|c|c|c|c|}
\hline \multirow{3}{*}{ Primary relay } & \multirow{3}{*}{ Back-up relay } & \multicolumn{6}{|c|}{ Operating time (sec) } \\
\hline & & \multicolumn{3}{|c|}{ Utility-only mode } & \multicolumn{3}{|c|}{ Grid-connected mode } \\
\hline & & Primary & Backup & CTI & Primary & Backup & CTI \\
\hline FCB2 & Main CB1 & $0.261(0.379)^{*}$ & $0.636(0.636)$ & $0.375(0.257)$ & $0.256(0.370)$ & $0.637(0.636)$ & $0.381(0.266)$ \\
\hline FCB3 & Main CB1 & $0.261(0.377)$ & $0.636(0.636)$ & $0.375(0.259)$ & $0.253(0.364)$ & $0.637(0.636)$ & $0.384(0.272)$ \\
\hline LCB4 & FCB2 & $0.100(0.144)$ & $0.300(0.379)$ & $0.2(0.235)$ & $0.099(0.140)$ & $0.299(0.370)$ & $0.2(0.23)$ \\
\hline LCB5 & FCB2 & $0.101(0.133)$ & $0.365(0.379)$ & $0.264(0.246)$ & $0.099(0.126)$ & $0.372(0.384)$ & $0.273(0.258)$ \\
\hline LCB6 & FCB2 & $0.016(0.019)$ & $0.458(0.461)$ & $0.442(0.442)$ & $0.017(0.019)$ & $0.463(0.467)$ & $0.446(0.448)$ \\
\hline LCB7 & FCB3 & $0.100(0.144)$ & $0.300(0.379)$ & $0.2(0.235)$ & $0.099(0.140)$ & $0.299(0.358)$ & $0.2(0.218)$ \\
\hline LCB8 & FCB3 & $0.101(0.133)$ & $0.365(0.379)$ & $0.264(0.246)$ & $0.099(0.122)$ & $0.380(0.381)$ & $0.281(0.259)$ \\
\hline LCB9 & FCB3 & $0.016(0.019)$ & $0.458(0.461)$ & $0.442(0.442)$ & $0.018(0.019)$ & $0.496(0.505)$ & $0.478(0.486)$ \\
\hline
\end{tabular}

${ }^{*}$ The corrected values are shown in parentheses.

TABLE 8: Fault currents at various locations in islanding mode.

\begin{tabular}{lccc}
\hline Location of fault & Relay & $\begin{array}{c}\text { Fault current (A) } \\
\text { Three-phase short circuit fault }\end{array}$ & $\begin{array}{c}\text { Fault current (A) } \\
\text { Single line-to-ground fault }\end{array}$ \\
\hline F1 & FCB2 & 382 & 384 \\
F2 & FCB3 & 360 & 363 \\
F3 & LCB4 & 420 & 128 \\
F4 & LCB5 & 458 & 443 \\
F5 & LCB6 & 416 & 334 \\
F6 & LCB7 & 482 & 166 \\
F7 & LCB8 & 515 & 187 \\
F8 & LCB9 & 555 & 241 \\
F9 & CB10 & 350 & 116 \\
F10 & CB 11 & 379 & 168 \\
F11 & CB 12 & 409 & 83 \\
F12 & CB 13 & 438 & 106 \\
\hline
\end{tabular}

TABLE 9: The taps and TDSs for all IEDs in islanding mode.

\begin{tabular}{lcccc}
\hline Relay & CT ratio & Tap of CO & Tap of LCO & TDS \\
\hline FCB2 & $600 / 5$ & 2.54 & 2.56 & \\
FCB3 & $600 / 5$ & 2.40 & 2.42 & \\
LCB4 & $1000 / 1$ & 0.33 & 0.10 & \\
LCB5 & $1000 / 1$ & 0.36 & 0.35 & \\
LCB6 & $1000 / 1$ & 0.33 & 0.27 & \\
LCB7 & $1000 / 1$ & 0.38 & 0.13 & 2 \\
LCB8 & $1000 / 1$ & 0.41 & 0.15 & \\
LCB9 & $1000 / 1$ & 0.44 & 0.19 & \\
CB10 & $1000 / 1$ & 0.28 & 0.09 & \\
CB11 & $1000 / 1$ & 0.30 & 0.13 & \\
CB12 & $1000 / 1$ & 0.32 & 0.07 & \\
CB13 & $1000 / 1$ & 0.35 & 0.08 & \\
\hline
\end{tabular}

contact point is vitrified by the heat of the arcs until the arcs finally cease. The waveform of the $3 I_{0}$ zero-sequence current clearly reflects the changes of the c-phase current, but not the currents of the other two phases or the three-phase voltages.

As stated above, conventional protection devices are not capable of protecting the microgrid from high impedance faults whether in grid-connected mode or in islanding mode. This study proposes a solution which combines wavelet transformer and neural network to build high impedance fault detecting IEDs, and the mother wavelet function [19] in which Db10 is selected for fault voltage and fault current signal decomposition is used. Five-level wavelet analysis with $10 \mathrm{kHz}$ sampling frequency is adopted to accurately extract the high-frequency transient of the arc phenomenon. The three phase voltages wavelet coefficients $d_{1}[n]$ may be used to identify the fault phase, and the $3 I_{0}$ zero-sequence fault current characteristic wavelet coefficients $d_{3}[n], d_{4}[n], d_{5}[n]$, and $c_{5}[n]$ may be used to identify high impedance faults, as shown in Figure 9.

The detection of high impedance faults may be considered as a complex process of pattern recognition. Because of the lack of sufficient fault detection knowledge, methods adopting neural network are suitable for high impedance fault detection. The data inputted to the neural network can be greatly simplified by performing series of norm calculations of the wavelet coefficients with $0.1 \mathrm{sec}$ data window. After extensive neural network training and testing, the result shows that the proposed method using IEDs combined with wavelet transformer and neural network can detect high impedance faults successfully [20].

\section{Conclusions}

The magnitudes and the directions of the fault currents may change because of the microsources of the microgrid 
in grid-connected mode as compared to those in utilityonly mode when a fault occurs in the system. Therefore the settings of the $\mathrm{CO} / \mathrm{LCO}$ relays must be reconfigured to protect the system effectively. The linear programming method is adopted to optimize the protection coordination. The relays coordination simulation software is used to check if the optimization result is in accordance with the actual timecurrent characteristic curves, and modifications will be made if needed.

While a CO relay can be used as the primary relay when there is a three-phase short circuit fault at the duty point of a high voltage customer, the protection coordination may not be accomplished due to insufficient CTI between LCO relay and LCB when a single line-to-ground fault occurs. This problem can be solved by using a power fuse instead of a CO/LCO relay as the primary protection device. Such solution is recommended by this study so that the faulted area is properly isolated and the system is protected when either a three-phase short circuit fault or a single line-to-ground fault occurs.

System protection coordination cannot be accomplished by conventional $\mathrm{CO} / \mathrm{LCO}$ relays alone when a microgrid operates in islanding mode. IEDs conforming to the IEC61850 communication protocol, capable of determining the direction of fault current, and equipped with multiply groups of trip settings are proposed in this study as protection devices. When a fault occurs while the system is in a certain operation mode, IEDs can decide if a trip signal should be issued according to the magnitude and direction of the fault current and if some protection devices should be blocked by GOOSE mechanism to minimize outage area and to improve power supply quality. Such type of protection coordination is very different from the conventional primary/back-up protection coordination.

As power systems with huge generators are gradually replaced by small and distributed microgrids, IEDs with IEC61850 GOOSE communication capability and with multiply groups of trip settings are recommended when power utilities replace their protection relays or install new ones. The use of such IEDs will insure that, whether in utility-only mode, grid-connected mode, or islanding mode, when a fault occurs in the system, a protection device management system can supervise and manage the protection coordination of the entire power system. It can not only isolate the faulty area quickly but also improve the power supply reliability to utility customers.

Because the arcs resulting from high impedance faults are random and nonlinear, IEDs combined with wavelet transformer and neural network are proposed in this study to identify the characteristic signals of high impedance faults.

\section{References}

[1] M. Xia, X. He, and X. Zhang, "Design and implementation of a control strategy for microgrid containing renewable energy generations and electric vehicles," Mathematical Problems in Engineering, vol. 2013, Article ID 686508, 15 pages, 2013.

[2] H. J. Laaksonen, "Protection principles for future microgrids," IEEE Transactions on Power Electronics, vol. 25, no. 12, pp. 29102918, 2010.
[3] IEEE Application Guide for IEEE Std 1547, IEEE Standard for Interconnecting Distributed Resources with Electric Power Systems IEEE Std 1547. 2-2008, pp. 1- 207, 2009.

[4] J.-Y. Kim, H.-M. Kim, S.-K. Kim, J.-H. Jeon, and H.-K. Choi, "Designing an energy storage system fuzzy PID controller for microgrid islanded operation," Energies, vol. 4, no. 9, pp. 14431460, 2011.

[5] B. Belvedere, "A microcontroller-based power management system for standalone microgrids with hybrid power supply," IEEE Transactions on Sustainable Energy, vol. 3, no. 3, pp. 422-431, 2012.

[6] M.-T. Yang and J.-C. Gu, "Optimal coordination of automatic line switches for distribution systems," Energies, vol. 5, no. 4, pp. 1150-1174, 2012.

[7] A. Liu and M.-T. Yang, "A new hybrid Nelder-Mead particle swarm optimization for coordination optimization of directional overcurrent relays," Mathematical Problems in Engineering, vol. 2012, Article ID 456047, 18 pages, 2012.

[8] "IEEE Standard Inverse-Time Characteristic Equations for Overcurrent Relays," IEEE Std C37.112-1996, 1997.

[9] W. K. A. Najy, H. H. Zeineldin, and W. L. Woon, "Optimal protection coordination for microgrids with grid-connected and islanded capability," IEEE Transactions on Industrial Electronics, vol. 60, no. 4, pp. 1668-1677, 2013.

[10] A. J. Urdaneta, R. Nadira, and L. G. Perez Jimenez, "Optimal coordination of directional overcurrent relays in interconnected power systems," IEEE Transactions on Power Delivery, vol. 3, pp. 903-911, 1988.

[11] E. Sortomme, S. S. Venkata, and J. Mitra, "Microgrid protection using communication-assisted digital relays," IEEE Transactions on Power Delivery, vol. 25, no. 4, pp. 2789-2796, 2010.

[12] IEC61850-6, Communication Networks and Systems in Substations Part 6: Configuration Description Language for Communication in Electrical Substations Related to IEDs.

[13] IEC61850-8-1, Communication Networks and Systems in Substations Part 8-1: Specific Communication Service Mapping (SCSM) Mappings to MMS, (ISO/IEC, 9506-1 and ISO/IEC, 9506-2) and to ISO/IEC, 8802-3.

[14] T. S. Ustun, C. Ozansoy, and A. Zayegh, "Modeling of a centralized microgrid protection system and distributed energy resources according to IEC 61850-7-420," IEEE Transactions on Power Systems, vol. 27, no. 3, pp. 1560-1567, 2012.

[15] N.-D. Nhat, G.-S. Kim, and H.-H. Lee, "A study on GOOSE communication based on IEC 61850 using MMS ease lite," in Proceedings of the International Conference on Control, Automation and Systems (ICCAS '07), pp. 1873-1877, Seoul, Republic of Korea, October 2007.

[16] A. P. Apostolov, "Implementation of accelerated transmission line protection schemes in substations with IEC 61850," in Proceedings of the IEEE/PES Transmission and Distribution Conference and Exhibition, pp. 1-6, Chicago, Ill, USA, April 2008.

[17] J. Piirainen, Applications of horizontal communication in industrial power networks [M.S. thesis], Tampere University of Technology, 2010.

[18] J.-C. Tan, V. Green, and J. Ciufo, “Testing IEC 61850 based multi-vendor substation automation systems for interoperability," in Proceedings of the IEEE/PES Power Systems Conference and Exposition (PSCE '09), pp. 1-5, Seattle, Wash, USA, March 2009. 
[19] C.-H. Kim, H. Kim, Y.-H. Ko, S.-H. Byun, R. K. Aggarwal, and A. T. Johns, "A novel fault-detection technique of high-impedance arcing faults in transmission lines using the wavelet transform," IEEE Transactions on Power Delivery, vol. 17, no. 4, pp. 921-929, 2002.

[20] M.-T. Yang and J.-C. Gu, "Detecting high impedance faults utilizing combined phase voltages with neutral line current," International Journal of Emerging Electric Power Systems, vol. 2, no. 2, article 1051, pp. 1-21, 2005. 


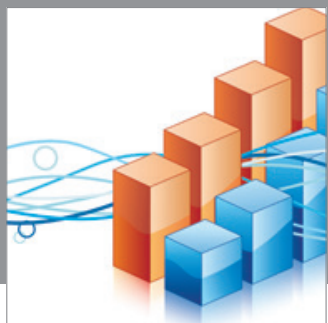

Advances in

Operations Research

mansans

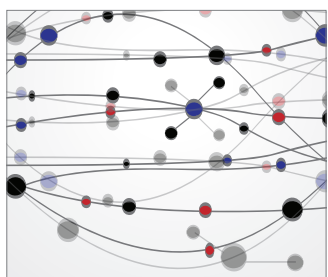

The Scientific World Journal
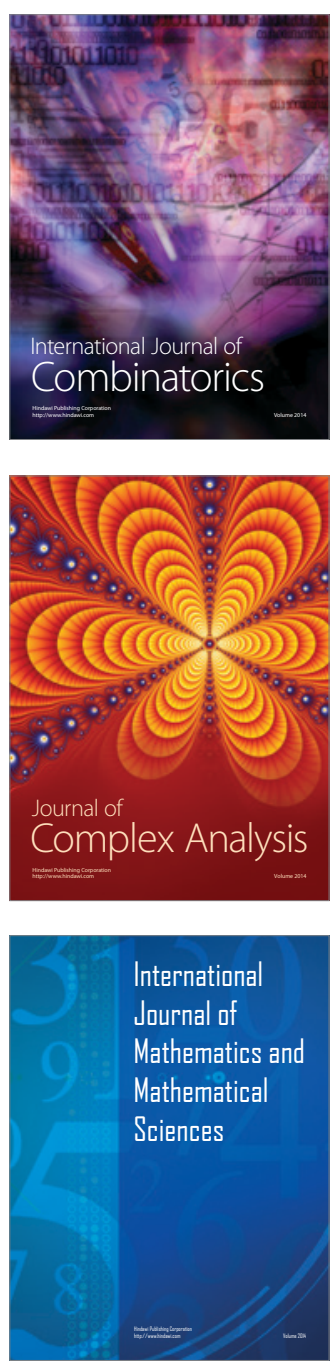
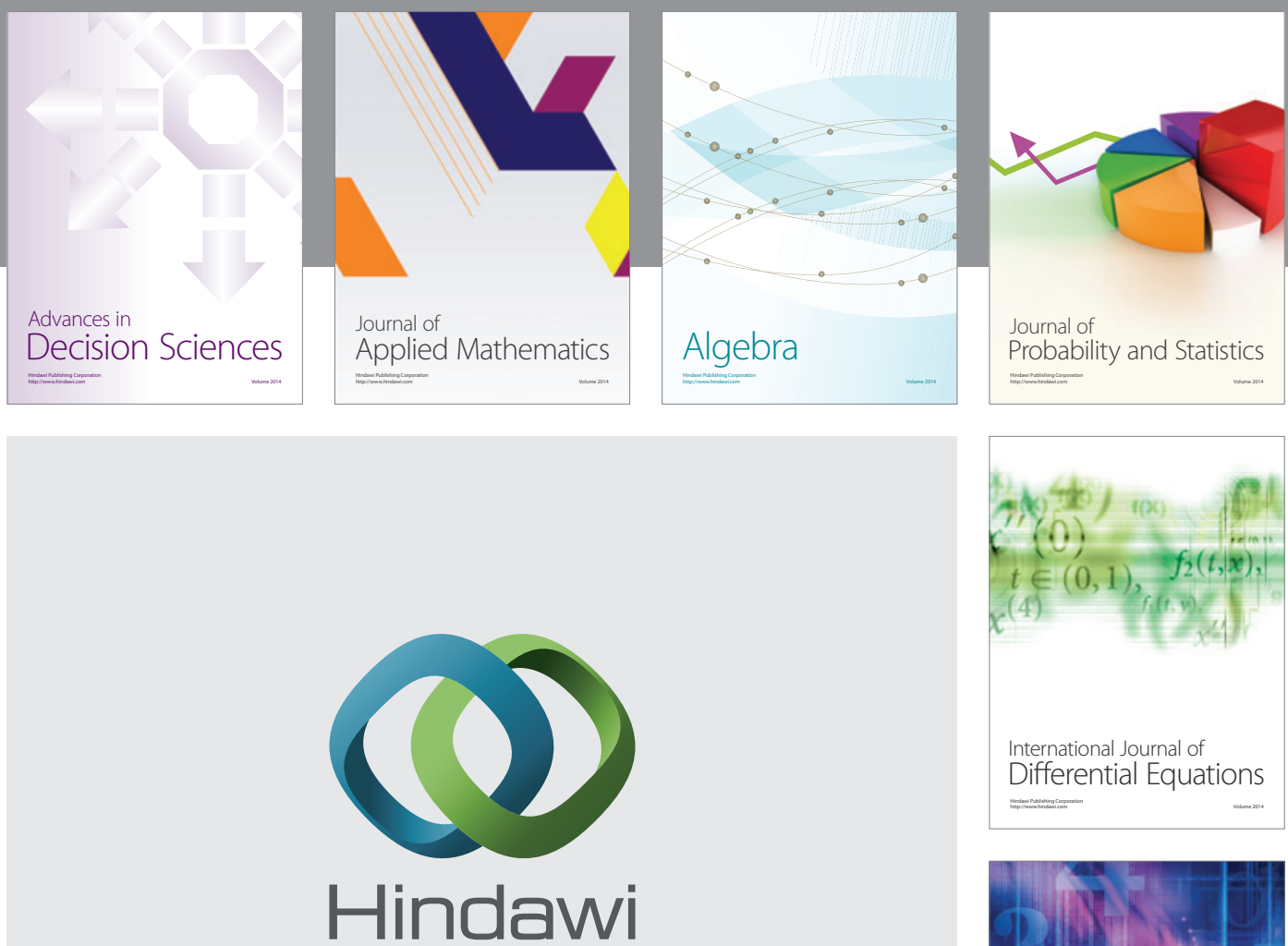

Submit your manuscripts at http://www.hindawi.com
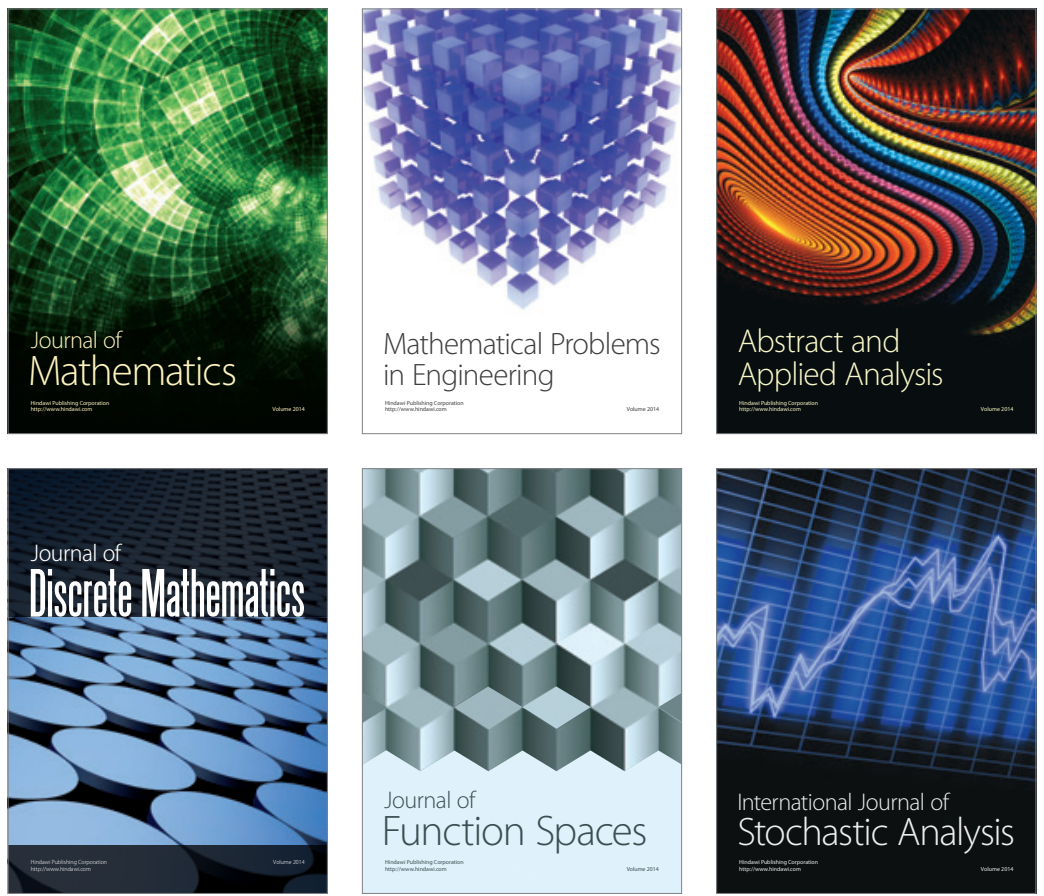

Journal of

Function Spaces

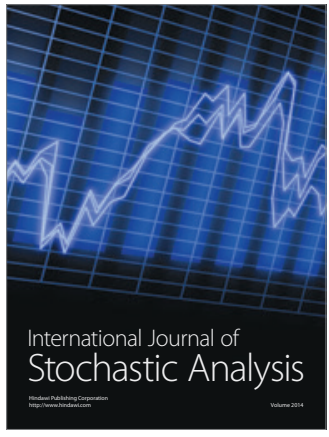

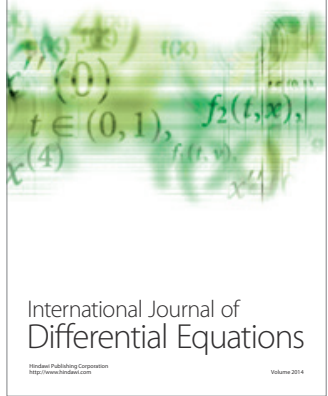
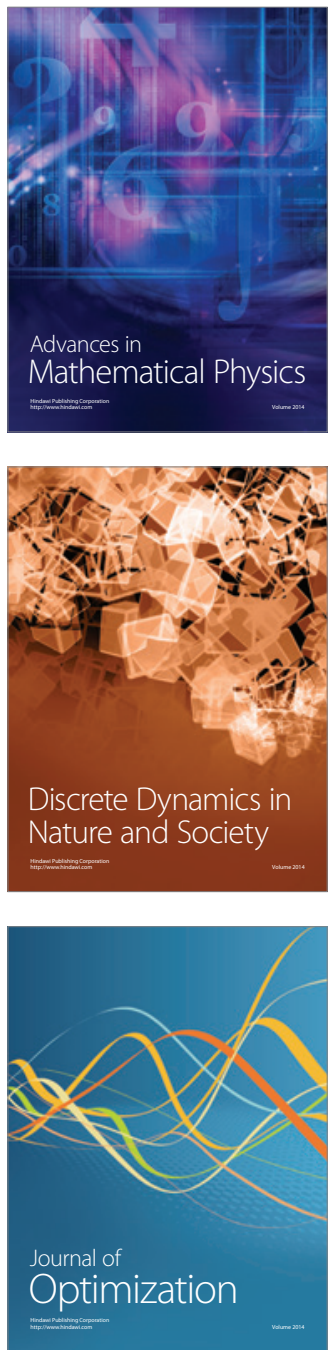